\title{
Dynamic Rheological Behavior of Chitosan/collagen Mixtures
}

\author{
MARICEL DANU ${ }^{1,2}$, BOGDANA SIMIONESCU ${ }^{3}$, CONSTANTA IBANESCU ${ }^{1,2}$, \\ SORIN ALEXANDRU IBANESCU ${ }^{* *}$ \\ ${ }^{1}$ Petru Poni Institute of Macromolecular Chemistry, 41A Grigore Ghica Voda Alley, 700487, Iasi, Romania \\ 2 Gheorghe Asachi Technical University of Iasi, Department of Natural and Synthetic Polymers, 73 Prof. Dimitrie \\ Mangeron Str., 700050, Iasi, Romania \\ ${ }^{3}$ Costin D. Nenitescu Centre of Organic Chemistry, 202B Splaiul Independentei, 71141, Bucharest, Romania
}

\begin{abstract}
Chitosan and collagen are naturally-derived materials with multiple applications, but their mixtures present phase separation phenomena. This shortcoming in relation to the mixture processing and, obviously, the applications can be overcome by choosing the appropriate composition. Rheological methods have been used to study collagen - chitosan mixtures to highlight their compatibility conditions in solution. Through the use of oscillatory rheometry, the viscoelastic behavior of collagen-chitosan mixtures in 0.5M acetic acid solution was analysed. The storage modulus $\left(G^{\prime}\right)$ was used to describe the elasticity of the material, while the loss modulus $\left(G^{\prime \prime}\right)$ provided information on the viscous behavior of the mixtures.
\end{abstract}

Keywords: chitosan, collagen, viscoelastic properties, rheological behaviour

\section{Introduction}

Both chitosan and collagen are naturally-derived materials with multiple applications in the biomedical field. Chitosan (CS) is a linear polysaccharide, copolymer of $\mathrm{N}$-acetyl-glucosamine and $\mathrm{N}$ glucosamine units, derived from the deacetylation of chitin, an abundant organic molecule. Due to the presence of reactive amino and hydroxyl groups, CS can be easily modified too and is able to form complexes with acids and polycarboxilic acids. Being a biocompatible and biodegradable polymer, presenting antimicrobial activity, wounds healing properties and low immunogenicity, CS is of great interest in numerous medical applications, especially in tissue engineering and the preparation of microparticles and microspheres with entrapped drugs for controlled delivery [1-5]. In acid medium ( $\mathrm{pH}$ values lower than 6.5), CS presents a polycationic character and it is soluble because of the transforming of neutral $-\mathrm{NH}_{2}$ groups into positively charged $-\mathrm{NH}_{3}{ }^{+}$. The amino groups can be easily used for active biological ligands anchorage. Collagen $(\mathrm{Col})$ is the most abundant structural protein found in the animal organs - in skin, tendon, cartilage and bone. The basic structure of Col, known as tropocollagen, consists of three polypeptide chains, each twisted in a left-handed helix ( $\alpha$-chain), and coiled around each other to form a right-handed triple super helix. Medical and pharmaceutical applications of collagen include its use in membranes, biodegradable films, wound and burns dressing, tumor treatment, and tissue engineering [6-10].

The specific properties of CS and Col may be used to produce blends or composite materials with new structural properties. CS-Col composite materials are suited for active principles encapsulation and controlled delivery, as injectable. The relation between the physicochemical characteristics of CS and its interactions with Col was previously investigated [11-16]. It has been found that CS can modify the behavior of $\mathrm{Col}$ when the biological or mechanical proprieties are evaluated. The thermal and mechanical characteristics of CS/Col films or fibers depend on the composition of the blend [1618]. The molecular interactions in polymer systems are due to specific interactions between polymeric partners, which give rise to a negative free energy of polymers mixing. Collagen and chitosan mixtures present phase separation phenomena, which, in terms of polymers compatibility theory, makes them

\footnotetext{
*email: ibanescu.sorin@icmpp.ro
} 
incompatible $[19,20]$. The continuous need to develop biomaterials to be used in tissue engineering or as carriers for controlled drugs delivery has highlighted the shortcomings created by phase separation in relation to mixture processing and, obviously, the applications of the system characteristics [21]. Applied research is focused on finding mixing conditions that avoid the phase separation phenomenon, taking into account the composition of the mixture, the $\mathrm{pH}$ of the environment, as well as the nature and the concentration of some additives which, through their properties, stimulate mixtures compatibility.

In view of the above mentioned, rheological methods have been used to study the collagen chitosan system in order to highlight the compatibility conditions of their mixtures in solution. Rheology is defined as the science of the deformation and flow of matter. It investigates the response of materials to an applied stress or strain [22, 23]. Rheological properties describe flow characteristics and textural behavior of substances. The success of a wide range of commercial products and industrial processes depends on meeting specific flow requirements. Rheological behavior can be generally divided in two types [24]: elastic behavior, where the material restores its original shape when the external force is removed, and viscous or plastic behavior (such as in ideal Newtonian liquids), where deformation ceases and the material does not regain its original shape when the applied force is removed [25]. Through the use of oscillatory rheometry the viscoelastic behavior of collagen-chitosan mixtures in $0.5 \mathrm{M}$ acetic acid solution was analyzed as a function of temperature. The storage modulus ( $G^{\prime}$-elastic modulus) describes the elasticity of the material, while the loss modulus (G"- viscous modulus) provides information on viscous behavior.

\section{Materials and methods}

Collagen has been obtained in our laboratory from bovine skin following a previously published procedure [16]. The protein has been extracted using a combined acid-alkaline treatment. The viscosity has been determined in $0.5 \mathrm{M}$ acetic acid solution, at $25^{\circ} \mathrm{C}([\eta]=4.256 \mathrm{dl} / \mathrm{g}$, isoelectric $\mathrm{pH}=4.82)$. CS with an average molecular weight of $\mathrm{M}_{\mathrm{w}}=94,800 \mathrm{~g} / \mathrm{mol}$, polydispersity index of 3.26 and deacetylation degree of $79.7 \%$ was purchased from Vanson, Inc. (Redmond, W.A. USA). The composite solutions were prepared by mixing appropriate volumes of collagen (1\%) and chitosan (1\%) in $0.5 \mathrm{M}$ acetic acid.

Rheological tests have been performed on a Physica MCR 501 modular rheometer (Anton Paar, Austria) equipped with an electronically commutated synchronous motor allowing rheological testing both in controlled stress (CS) and control strain (CR) modes. Parallel-plate geometry with a diameter of $25 \mathrm{~mm}$ was selected as a measuring system. The samples were heated using the rheometer Peltier system. All rheological characteristics were determined in dynamic oscillation mode [26, 27]. The measurements were performed at least three times to verify the reproducibility.

\section{Measurements}

The amplitude sweep is used to determine the limit of the linear viscoelastic (LVE) range. Here, the oscillation frequency is kept constant $(\omega=10 \mathrm{rad} / \mathrm{s})$, while the oscillation amplitude $(\gamma)$ is varied (between 0.01 and 100\%). The limit of the LVE range allows the determination of the maximum deformation tolerated by the sample before the internal super-structure is destroyed.

The frequency sweep is a widely used standard test in material rheology. In this test a sinusoidal strain with a constant amplitude $(\gamma=0.1-1 \%)$ is applied and the oscillation frequency is varied (between 0.01 and $100 \mathrm{rad} / \mathrm{s}$ ). All measurements were carried out at $20^{\circ} \mathrm{C}$ constant temperature.

Flow curves were recorded in the 0.1 to $100 \mathrm{~s}^{-1}$ domain at $20^{\circ} \mathrm{C}$ constant temperature.

Dynamic temperature sweep tests were induced after equilibration at the initial temperature $\left(20^{\circ} \mathrm{C}\right)$. The samples were heated from $20^{\circ} \mathrm{C}$ to $50^{\circ} \mathrm{C}$ at a $0.5^{\circ} \mathrm{C} / \mathrm{min}$ rate at a constant angular frequency of 10 $\mathrm{rad} / \mathrm{s}$ and a constant strain in the linear viscoleastic region. Temperature test was performed in a dynamic oscillation (constant strain) mode (typically, strain amplitude and frequency $=0.1 \%$ and $1 \mathrm{~Hz}$, respectively). 
The results were presented as the variation of the storage modulus, the loss modulus, and/or tan $\delta$ with temperature.

\section{Results and discussions}

A series of samples with different ratio between collagen and chitosan were prepared with the composition described in Table 1. The mixtures presented a structure ranging from liquid-like to gellike, depending on composition. Dynamic oscillatory rheology was used to investigate the mixtures viscoelastic behavior in order to determine the compatibility conditions between the two components.

Table 1. Composition of the analyzed samples

\begin{tabular}{|c|c|c|c|}
\hline Sample & Code & Collagen $(\boldsymbol{\%})$ & Chitosan $(\%)$ \\
\hline 1 & $90 / 10(\mathrm{Col} / \mathrm{CS})$ & 90 & 10 \\
\hline 2 & $80 / 20(\mathrm{Col} / \mathrm{CS})$ & 80 & 20 \\
\hline 3 & $70 / 30(\mathrm{Col} / \mathrm{CS})$ & 70 & 30 \\
\hline 4 & $60 / 40(\mathrm{Col} / \mathrm{CS})$ & 60 & 40 \\
\hline 5 & $50 / 50(\mathrm{Col} / \mathrm{CS})$ & 50 & 50 \\
\hline 6 & $40 / 60(\mathrm{Col} / \mathrm{CS})$ & 40 & 60 \\
\hline 7 & $30 / 70(\mathrm{Col} / \mathrm{CS})$ & 30 & 70 \\
\hline 8 & $20 / 80(\mathrm{Col} / \mathrm{CS})$ & 20 & 80 \\
\hline 9 & $10 / 90(\mathrm{Col} / \mathrm{CS})$ & 10 & 90 \\
\hline 1.1 & $0 / 100(\mathrm{Col} / \mathrm{CS})$ & 0 & 0 \\
\hline 1.2 & $100 / 0(\mathrm{Col} / \mathrm{CS})$ & 100 & \\
\hline
\end{tabular}

\section{Amplitude sweep}

A $10 \mathrm{rad} / \mathrm{s}$ frequency strain sweep test was performed to determine the linear viscoelastic region, from which an appropriate strain was selected (Figure 1). Viscoelastic properties of the network were evaluated by recording the evolution of the dynamic moduli, G' and G'. The evolution of the storage modulus $\left(G^{\prime}\right)$ gives information about the solid-like (elastic) behavior of the sample, while the loss modulus (G”) offers information about the liquid-like (viscous) behavior [26, 28]. The deformation limit resulting from the amplitude sweep data is between $0.1-1 \%$. As can be easily noticed from Figure 1 and Table 2, stable liquid structures are obtained for materials with low collagen content, while the addition of collagen determines the development of stiffer gel structures. The $\tan \delta$ values are supporting this observation.

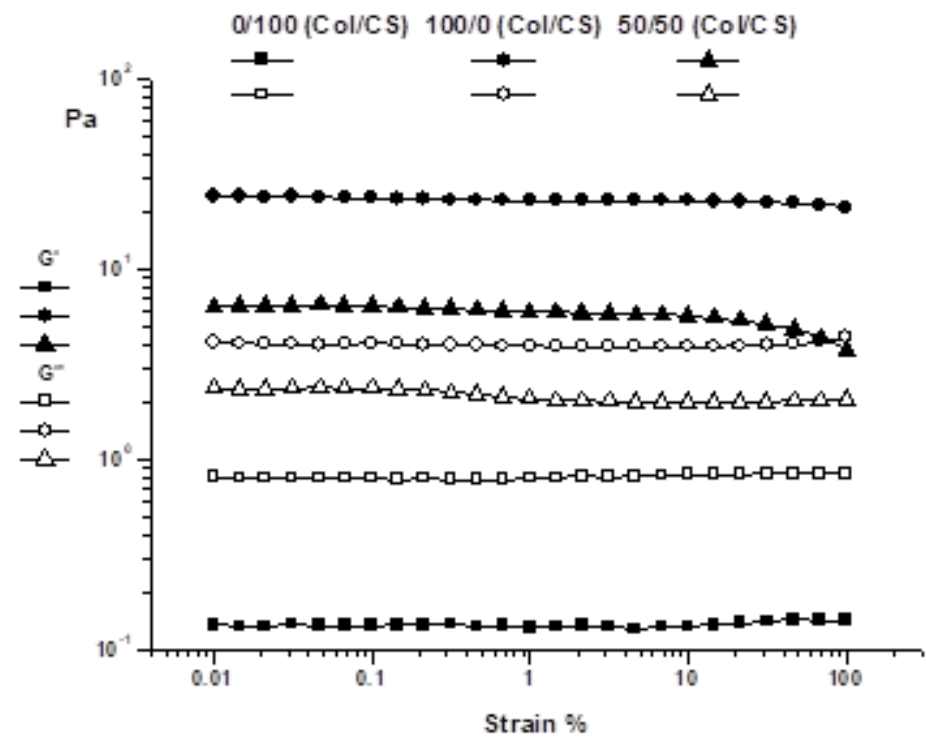

Figure 1. Amplitude sweep for 0/100 (Col/CS), $100 / 0(\mathrm{Col} / \mathrm{CS})$ and 50/50 (Col/S) samples 
Determination of the linear dynamic moduli at small deformation amplitude (Table 2) showed that all collagen-containing materials are stiffer than the sample containing only chitosan. This observation is in agreement with the assumption of protein network formation in which polysaccharide particles are included. The $\mathrm{G}^{\prime}$ minimum value $(0.13 \mathrm{~Pa})$ was recorded for $0 / 100(\mathrm{Col} / \mathrm{CS})$ sample, while $100 / 0$ $(\mathrm{Col} / \mathrm{CS})$ had a $\mathrm{G}$ ' value of $23.76 \mathrm{~Pa}$. The rheological results led to the idea of tailoring mixtures with different proprieties varying from structured liquids to hydrogels, suitable for a wide range of applications.

Table 2. Dynamic moduli (G' and G') and tan $\delta$ for $\gamma=0.1 \%$

\begin{tabular}{|c|c|c|c|c|c|c|c|c|c|c|c|}
\hline Sample & $\mathbf{1 . 2}$ & $\mathbf{1}$ & $\mathbf{2}$ & $\mathbf{3}$ & $\mathbf{4}$ & $\mathbf{5}$ & $\mathbf{6}$ & $\mathbf{7}$ & $\mathbf{8}$ & $\mathbf{9}$ & $\mathbf{1 . 1}$ \\
\hline G' (Pa) & 23.76 & 76.75 & 19.20 & 23.24 & 5.87 & 5.97 & 5.80 & 1.93 & 4.58 & 0.65 & 0.13 \\
\hline G' (Pa) & 4.00 & 5.16 & 2.89 & 3.43 & 2.39 & 2.08 & 1.97 & 1.62 & 2.12 & 0.84 & 0.80 \\
\hline $\tan (\boldsymbol{\delta})$ & 0.16 & 0.06 & 0.15 & 0.14 & 0.40 & 0.34 & 0.33 & 0.83 & 0.46 & 1.29 & 6.15 \\
\hline
\end{tabular}

\section{Frequency sweep}

Storage modulus (G') and the loss modulus (G') were measured from a constant strain frequency sweep over a 0.1-100 rad/s frequency range. Figure 2 (a), (b), (c) and (d) shows the frequency dependence of the dynamic moduli ( $G^{\prime}$ and $\left.G^{\prime \prime}\right)$, as well as the complex viscosity, at $20^{\circ} \mathrm{C}$ for all collagen/chitosan mixtures. This temperature was chosen in order to avoid the denaturation of the samples. As expected, the storage modulus becomes higher than the loss modulus when collagen content is increased, suggesting the development of a gel structure. The dependence of G' and G" on frequency suggests a greater contribution of physical bonds in the network formation. The strongest influence of frequency on G' and only a slight increase of $G$ ' with frequency is characteristic for physical hydrogel materials [29-31] (Figure 2). The gel strength and its mechanical and structural stability can be appreciated by the magnitude of G' and by the difference between G' and G' [32]. Figure 2 (e) and (f) presents the variation with frequency for the complex viscosity of the biopolymers mixtures. For all samples a shear thinning behavior is characteristic as $\eta^{*}$ is increasing with the increase in frequency [33]. Different structures are obtained for different component ratios. The molecular interaction that can exist in aqueous medium, at acidic values, between the cationic polyelectrolyte chitosan and the amphoteric polyelectrolyte collagen are: (1) the electrostatic repulsions between the positively charged entities and (2) the hydrogen bonds and hydrophobic interactions among the biopolymer chains. In the present case, the structures are stabilized mostly by the second type of interactions, i.e. hydrogen bonds and hydrophobic interactions. With the addition of chitosan to collagen, a decrease of the storage modulus, the viscous loss modulus and the apparent viscosity (as a function of frequency) is observed [34]. It was also found that collagen/chitosan systems can exhibit both fluid-like and solid-like viscoelastic behaviors depending on the percentage of the two components [25].

Analysing the results from the mechanical spectra of the protein/polyssacharide mixtures, important data on materials designed for specific applications can be obtained. Harder or softer support materials may be manufactured by choosing the appropriate protein/polyssacharide ratio. Significant information for the polymer processing operation can be also obtained.

\section{Flow curves}

The flow curves (Figure 3) were recorded at $20^{\circ} \mathrm{C}$ for increasing shear rates. The chitosan solution has a non-Newtonian behavior for low shear rates and a Newtonian plateau for higher shear rates. The collagen solution has a typical non-Newtonian character with a clear Newtonian domain for low shear rates allowing the calculation of zero-shear viscosity. By the addition of chitosan the non-Newtonian character of mixtures diminishes and the zero-shear viscosity decreases. Obviously, the increase of the collagen content modifies the structure and the physical interactions in the blends. The shear-thinning 
behavior of the collagen/chitosan mixtures, characteristic for a lot of biopolymeric systems of great technical and practical importance is of outstanding importance for many processing and handling techniques [35]. These materials are not a constant material property, but will reasonably depend upon the state of stress the solution is subjected to. All the analysed samples behave as typical nonNewtonian shear-thinning fluids exhibiting wide Newtonian plateaus for low shear rates [36]. This behavior is due to the orientation of the dispersed asymmetric molecules occurring in shear stress experiments. When the shear rate increases, this effect will become more pronounced and will cause a decrease of the internal friction due to the smaller effective interaction between the molecules.
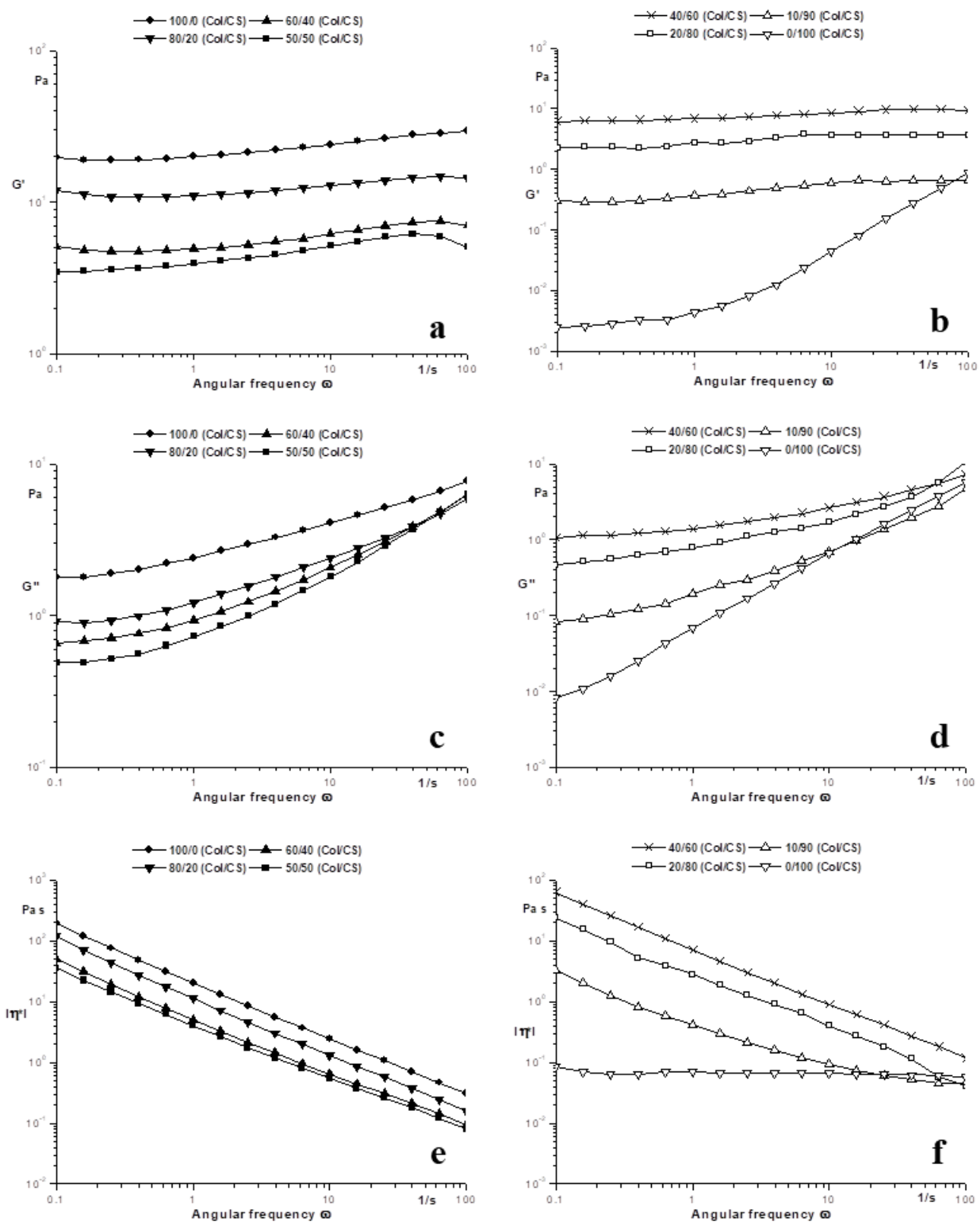

Figure 2. Frequency sweep results for the collagen/chitosan mixtures at different composition ratios: (a), (b) storage modulus; (c), (d) loss modulus; (e), (f) complex viscosity

Figure 3 depicts the apparent viscosity dependence on shear rate for all the analysed collagen/chitosan mixtures. The initial Newtonian zone is clear as well as the pseudoplastic character of all materials [34]. The shear thinning behavior of collagen/chitosan blends becomes more pronounced when collagen proportion is increased [25, 37, 38]. 

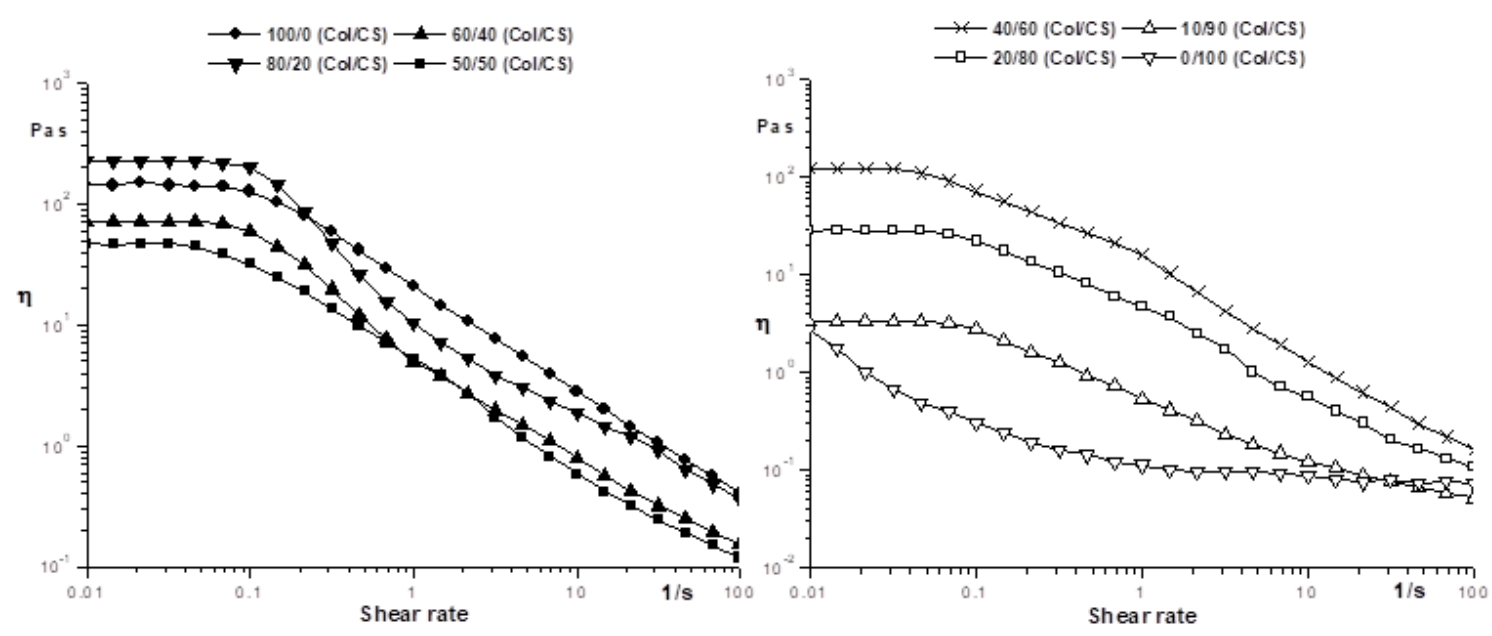

Figure 3. Flow curves for collagen/chitosan mixtures

\section{Temperature test}

The storage modulus $\left(\mathrm{G}^{\prime}\right)$ describes the elasticity of the material whereas the loss modulus (G") reflects the dissipated energy as a measure of the viscous properties [39]. The mechanical properties, as a function of temperature for collagen/chitosan mixtures, have been determined using oscillatory rheometry for a temperature range between $20^{\circ}$ and $50^{\circ} \mathrm{C}$ (Figure 4).

The dynamic moduli of collagen/chitosan mixtures, as a function of temperature, were found to be similar to those of pure collagen (Figure 4). The storage modulus, G', and the loss modulus, G', corresponding to the pure collagen solution and the collagen/chitosan mixtures (Figure 4(a) and 4(b)) slightly decreased with increasing temperature and presented a sharp modification at $22-30^{\circ} \mathrm{C}$, reflecting the denaturation process typical for pure collagen and collagen/chitosan mixtures [40]. Figure 4 (c) shows the variations of $\tan \delta$ as a function of temperature. The loss factor, $\tan \delta=\mathrm{G}^{\prime \prime} / \mathrm{G}^{\prime}$, characterizes the contributions of elastic and viscous portions in the overall behavior of the analysed sample. Generally, for the liquid state $\tan \delta>1\left(\mathrm{G}^{\prime \prime}>\mathrm{G}^{\prime}\right)$, and for the solid state $\tan \delta<1$ ( $\left.\mathrm{G}^{\prime}>\mathrm{G}^{\prime \prime}\right)$. The state transition or gelling point appears at $\tan \delta=1,\left(\mathrm{G}^{\prime}=\mathrm{G}^{\prime \prime}\right)$. Below $30^{\circ} \mathrm{C}, \tan \delta$ values were lower than 1 for all samples reflecting the gel or solid-like structure of the materials. The exceptions are the chitosan solution and the mixture with the lowest collagen content for which $\tan \delta$ is above 1 , exhibiting a liquid-like behavior. The rapid increase in $\tan \delta$ with temperature reflects the denaturation process of protein present in the samples [33]. Structural changes of the collagen, like decay of bioactivity, may happen as an influence of the temperature [35].
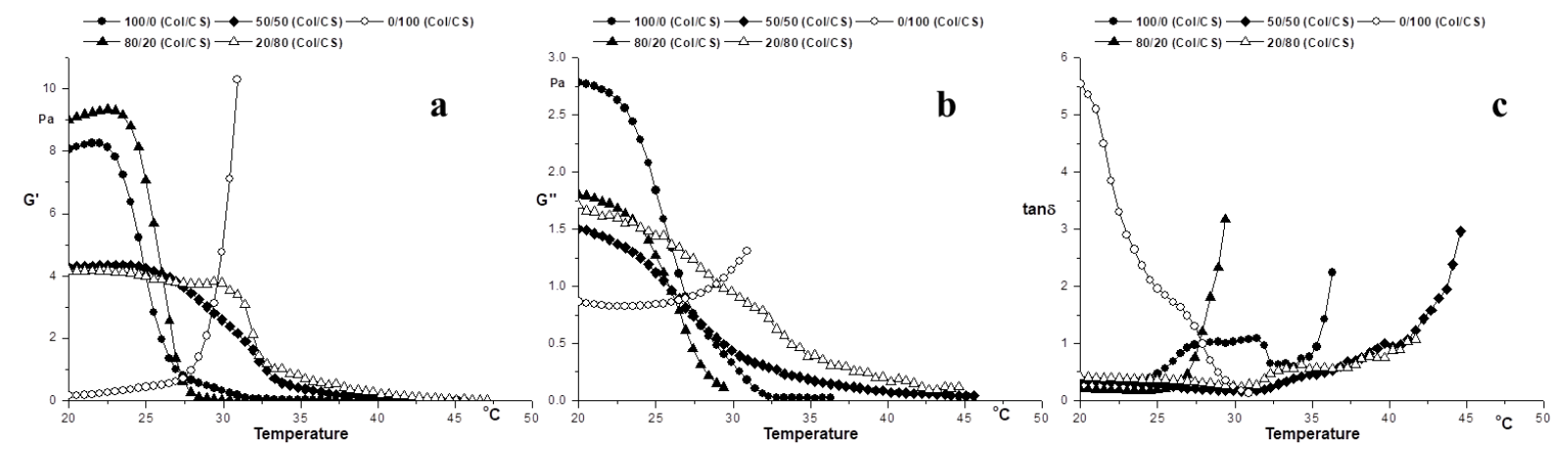

Figure 4. Temperature dependence of (a) G', (b) G', and (c) tan $\delta$ for collagen/chitosan samples 


\section{Conclusions}

Due to the importance of rheology for various products and processes including the design of collagen/chitosan based materials for specific applications, this article attempted to analyse the applicability of rheological studies in tailoring desired material properties. For the above mentioned reasons and as a result of recent development of biomaterials issued from chitosan/collagen mixtures, we were interested to study the interaction between chitosan and collagen. A series of collagen/chitosan mixtures have been studied using simple and oscillatory rheological tests. The rheological parameters controlling processing, mechanical stability and application of these materials have been determined. All the studied systems exhibited gel-like behavior, with different consistencies and degrees of structural stability. A good correlation between rheological parameters and systems structure was found.

Acknowledgments. This work has been performed in the frame of the Complex Projects Partnership Program CDI (PCCDI) in priority areas - PN III under UEFISCDI authority, project code PN-III-P11.2-PCCDI-2017-0083 (project number 37PCCDI/2018) and H2020 ERA Chairs Project no. 667387: SupraChem Lab Laboratory of Supramolecular Chemistry for Adaptive Delivery Systems ERA Chair initiative.

\section{References}

1. OHKAWA, K., YAMADA, M., NISHIDA, A., NISHI, N., YAMAMOTO, H.: J. Polym. Environ. 8, nr. 2, 2000, p. 59.

2. HAIDAR, Z.S., HAMDY, R.C., TABRIZIAN, M., Biomaterials 29, nr. 9, 2008, p. 1207.

3. DING, P., HUANG, K.-L., LI, G.-Y., LIU, Y.-F., Int. J. Biol. Macromol. 41, nr. 2, 2007, p. 125.

4. XU, Y., ZHAN, C., FAN, L., WANG, L., ZHENG, H., Int. J. Pharm. 336, nr. 2, 2007, p. 329.

5. NOVAC, O., POPA, M.I., AELENEI, N., MELNIG, V., Rev. Roum. Chim. 54, nr. 7, 2009, p. 539.

6. RAMSHAW, J.A.M.,. J. Biomed. Mater. Res - Part B App. Biomat. 104, nr. 4, 2016, p. 665.

7. ASGHARI, F., SAMIEI, M., ADIBKIA, K., AKBARZADEH, A., DAVARAN, S., Artif. Cell. Nanomed. B , 45, nr. 2, 2017, p. 185.

8. DONG, C., LV, Y., Polymers 8, nr. 2, 2016, p. 42.

9. SIONKOWSKA, A., SKRZYŃSKI, S., ŚMIECHOWSKI, K., KOŁODZIEJCZAK, A., Polym. Adv. Techn., 28, nr. 1, 2016, p. 4.

10.FERREIRA, A.M., GENTILE, P., CHIONO, V., CIARDELLI, G., Acta Biomater. 8, nr. 9, 2012, p. 3191.

11.MOREIRA, C.D.F., CARVALHO, S.M., MANSUR, H.S., PEREIRA, M.M., Mater Sci Eng C Mater Biol Appl., 58, 2016, p. 1207.

12. DA SILVA, M.A., BODE, F., DRAKE, A.F., GOLDONI, S., STEVENS, M.M., DREISS, C.A.,. Macromol. Biosci. 14, 2014, p. 817.

13. MA, L., Biomaterials 24, 2003, p. 4833.

14. OWCZARZ, P., RYŁ, A., MODRZEJEWSKA, Z., DZIUBŃSKI, M., Prog. Chem. Appl. Chitin its Deriv. 22, 2017, p.176.

15. SIONKOWSKA, A., Biomaterials 25, 2004, p. 795.

16. NASTASESCU, O.S., POPA, M.I., LISA, G., VERESTIUC, L., Rev. Roum. Chim. 54, nr. 7, 2009 , p. 549.

17.SIONKOWSKA, A., WISNIEWSKI, M., SKOPINSKA, J., POGGI, G.F., MARSANO, E., MAXWELL, C.A., WESS, T.J., Polym. Degrad. Stab. 91, 2006, p. 3026.

18. CHEN, Z., WEI, B., MO, X., LIM, C.T., RAMAKRISHNA, S., CUI, F., Mater. Sci. Eng. C. 29, 2009 , p. 2428.

19. HIEMENZ, P.C., RAJAGOPALAN, R.: Colloid and Surface Chemistry: In: Principles of Colloid and Surface Chemistry $3^{\text {rd }}$ Ed., CRC Press, ISBN 9780824793975, 1997, p.90-120. 
20. SIMONET, F., GARNIER, C., DOUBLIER, J.L., Food Hydrocoll. 14, nr. 6, 2000, p. 591.

21. YANG, H., ZHU, P., PENG, C., MA, S., ZHU, Q., FAN, C., Eur. Polym. J. 37, 2001, p. 1939.

22. BARNES, H.A.: A Handbook of Elementary Rheology, The University of Wales Institute of NonNewtonian Fluid Mechanics, Aberystwyth, Dyfed, Wales, UK, ISBN 0-9538032-0-1, 2000, p.1-9

23. MEZGER, T.G.: The Rheology Handbook, 3rd Revised Edition, Vincenz Network, Hanover, Germany, 2011, p. 16-26.

24. LEE, C.H., MOTURI, V., LEE, Y., J. Control. Release 136, nr. 2, p. 88.

25. EL-HEFIAN, E. A, YAHAYA, A.H., Maejo Int. J. Sci. Technol. 4 nr. 02, 2010, p. 210.

26. DANU, M., ROTARU, I., IBĂNESCU, C., HURDUC, N., IBǍNESCU, S.A., SIMIONESCU, B.C., Environ. Eng. Manag. J. 11, nr. 11, 2012, p. 1883.

27. IBĂNESCU, C., DANU, M., NANU, A., LUNGU, M., SIMIONESCU, B.C.: Stability of disperse systems estimated using rheological oscillatory shear tests. Rev. Roum. Chim. 55, nr. 11-12, 2010, p. 933.

28. SIMIONESCU, B., IBANESCU, S.A., DANU, M., ROTARU, I., IBANESCU, C.: Rheology of gelatin - starch systems I. Influence of system composition. Rev. Chim., 64, (8), 2013, 909.

29. CLARK, A.H., RICHARDSON, R.K., ROSS-MURPHY, S.B., STUBBS, J.M., Macromolecules 16, nr. 8, 1983, p. 1367.

30. NISHINARI, K., Colloid Polym. Sci. 275, 1997, p. 1093.

31. NYSTRÖM, B., WALDERHAUG, H., HANSEN, F.K., LINDMAN, B., Langmuir 11, nr. 3, 1995, p. 750.

32. CHEnite, A., BUSChMANn, M., WANG, D., CHAPUT, C., KANDANI, N., Carbohydr. Polym. 46, 2001, p. 39.

33. LAI, G., DU, Z., LI, G., Korea Aust. Rheol. J. 19, nr. 2, 2007, p. 81.

34. MACHADO, A.A.S., MARTINS, V.C.A., PLEPIS, A.M.G., J. Therm. Anal. Calorim. 67, 2002, p. 491.

35. WAWRO, D., STEPLEWSKI, W., BRZOZA-MALCZEWSKA, K., ŚWIESZKOWSKI, W., Fibres Text. East. Eur. 20, nr. 6B (96), 2012, p. 32-39.

36. MUCHA, M.,. Macromol. Chem. Phys. 198, nr. 2, 1997, p. 471.

37. KIENZLE-STERZER, C.A., RODRIGUEZ-SANCHEZ, D., RHA, C.K., Polym. Bull. 13, nr. 1, 1985, p. 1.

38. KWAN HWANG, J., SHIN, H.H.: Rheological properties of chitosan solutions., Korea Aust. Rheol. J. 12, nr. 3/4, 2000, p. 175.

39. FRIESS, W., SCHLAPP, M., Eur. J. Pharm. Biopharm. 51, nr. 3, 2001, p. 259.

40. KORHONEN, M., HELLEN, L., HIRVONEN, J., YLIRUUSI, J., Int. J. Pharm. 221, nr. 1-2, 2001, p. 187.

$\overline{\text { Manuscript received: } 3.12 .2019}$ 